Case Report

\title{
Genomic analysis of exceptional responder to regorafenib in treatment-refractory metastatic rectal cancer: a case report and review of the literature
}

\author{
Krittiya Korphaisarn ${ }^{1,2}$, Jonathan M. Loree ${ }^{1}$, Van Nguyen $^{3}$, Ryanne Coulson ${ }^{1}$, \\ Vijaykumar Holla ${ }^{4}$, Beate C. Litzenburger ${ }^{4}$, Ken Chen ${ }^{4}$, Gordon B. Mills ${ }^{4}$, Dipen M. \\ Maru, ${ }^{5}$, Funda Meric-Bernstan ${ }^{4}$, Kenna R. Mills Shaw ${ }^{4}$ and Scott Kopetz ${ }^{1}$ \\ ${ }^{1}$ Department of Gastrointestinal Medical Oncology, The University of Texas MD Anderson Cancer Center, Houston, Texas, \\ USA \\ 2 Department of Medicine, Division of Medical Oncology, Faculty of Medicine Siriraj Hospital, Bangkok, Thailand \\ ${ }^{3}$ Department of Pharmacy, The University of Texas MD Anderson Cancer Center, Houston, Texas, USA \\ ${ }^{4}$ Sheikh Khalifa Bin Zayed AI Nahyan Institute for Personalized Cancer Therapy (IPCT), The University of Texas MD Anderson \\ Cancer Center, Houston, Texas, USA \\ ${ }^{5}$ Department of Pathology, The University of Texas MD Anderson Cancer Center, Houston, Texas, USA \\ Correspondence to: Scott Kopetz, email: Skopetz@mdanderson.org \\ Keywords: metastatic colorectal cancer, regorafenib, survival, biomarker, response \\ Received: March 29, $2017 \quad$ Accepted: May 20, $2017 \quad$ Published: June 03, 2017
}

Copyright: Korphaisarn et al. This is an open-access article distributed under the terms of the Creative Commons Attribution License 3.0 (CC BY 3.0), which permits unrestricted use, distribution, and reproduction in any medium, provided the original author and source are credited.

\section{ABSTRACT}

We present the case of a 53-year-old male with metastatic rectal cancer who was treatment resistant to FOLFOX and FOLFOXIRI. Due to a Kirsten rat sarcoma viral oncogene homolog (KRAS) mutation, regorafenib was given in the third line setting. Surprisingly, the patient had a prolonged partial response that lasted 27 months. Mutational status was extensively evaluated to identify potential alterations that might play a role as predictive markers for this unusual event. A poorly characterized but nontransforming mutation in Fms-like tyrosine kinase 4 (FLT4) was present in the tumor. Prior to and at the time of clinical progression, we found amplification of fibroblast growth factor receptor 1 (FGFR1) and epidermal growth factor receptor (EGFR), loss of the FLT4 mutation, and gain of KIT proto-oncogene receptor tyrosine kinase (KIT) G961S suggesting potential roles in acquired resistance.

\section{INTRODUCTION}

Regorafenib, an oral multikinase inhibitor, is used in treatment refractory metastatic colorectal cancer (mCRC) after failure of fluoropyrimidine, irinotecan, and oxaliplatin based therapies. In $R A S$ wild type patients, progression following EGFR targeted therapy should also occur before use of regorafenib. The CORRECT clinical trial [1] demonstrated an overall survival (OS) benefit of regorafenib over placebo in treatment-refractory mCRC (6.4 months vs 5 months, Hazard ratio (HR) 0.77, $95 \%$ confidential interval $(\mathrm{CI}), 0.64-0.94, P=0.0052)$. Mean duration of regorafenib treatment was 2.8 months with an objective response rate only being $1 \%(5 / 505)$. The benefit of regorafenib was also reported in Asian populations in the CONCUR trial [2], which demonstrated an extended OS in regorafenib treated patients compared to placebo ( 8.8 vs 6.3 months, $\mathrm{HR}=0.55,95 \%$ CI 0.44 $0.77, P=0.00016)$. However, there are no biomarkers predicting response to this drug and many patients suffer early progression during treatment with regorafenib. An extensive analysis of circulating tumor DNA and proteins from the CORRECT trial attempted to identify biomarkers able to predict response, however was unsuccessful [3]. Here, we report a case of an unusual deep and longterm response to regorafenib and present the molecular characterization of this patient to help elucidate potential determinants of this exceptional response. 


\section{CASE REPORT}

A 53-year-old male presented with lower abdominal pain, constipation, intermittent episodes of bright red blood per rectum, and significant weight loss of 20 pounds over 3 months. He had no significant past medical or family history, and physical examination was normal. The patient underwent a colonoscopy which demonstrated an exophytic mass in the rectum causing partial obstruction. Biopsy revealed moderate to poorly differentiated adenocarcinoma arising from a villous adenoma with high grade dysplasia. Staging investigations revealed liver limited multiple metastases, with the largest mass measuring 12 centimeters. Carcinoembryonic antigen (CEA) was within normal limit.

A 200 gene next generation sequencing (NGS) panel was performed on the biopsied primary and identified a $K R A S$ mutation in codon G12S, a tumor protein p53 (TP53) mutation in codon $\mathrm{R} 273 \mathrm{C}$, an adenomatous polyposis coli (APC) mutation in codon $\mathrm{R} 1450^{*}$ and $\mathrm{I} 742 \mathrm{fs} *$, a protein phosphatase 1 regulatory subunit 3A (PPP1R3A) mutation in codon E271D, and a FLT4mutation, in codon F131S. FLT4, also known as vascular endothelial growth factor receptor 3 (VEGFR3) [4], is a member of the VEGFR family which can be targeted by regorafenib [5]. Since high VEGFR protein expression has been reported on colorectal cancer cells [6], we assessed the functional significance in the $\mathrm{Ba} / \mathrm{F} 3$ cell reporter assay. This screen showed no IL-3 independent growth which is a surrogate for the transforming ability of this variant in FLT4. Molecular characterization of the tumor is shown in Table 1. CpG island methylator phenotype (CIMP) was high (abnormal methylation in $6 / 6$ target genes) and microsatellite instability testing by immunohistochemistry demonstrated a microsatellite stable tumor.
Due to the patient's prior rectal bleeding and insitu primary malignancy, FOLFOX was initiated with bevacizumab omitted. After 4 cycles of treatment, interval CT scan showed progression of the hepatic metastases and rectal mass according to the Response Evaluation Criteria in Solid Tumors (RECIST) version 1.1 guideline [7]. The patient's treatment was changed to FOLFIRINOX, with an initial partial response (PR) after 4 cycles. However, after 8 cycles the patient once again demonstrated progressive disease in the liver and rectum. The patient was subsequently started on regorafenib at a dose of 120 mg per day for 3 weeks each 28-day cycle as per MD Anderson's institutional dosing practice. Interval CT scan of abdomen after 2 months showed a dramatic response. Hepatic metastases decreased in size from 9.8 to 7.7 in the left lobe and 11.6 to 9.3 centimeters $(\mathrm{cm})$ in the right lobe which was confirmed after 4 months. He continued on treatment without any dosing modifications. After 10 months of regorafenib, he required a dose reduction due to grade 2 hand-foot skin reaction (HFSR) which was most pronounced on the third week of each cycle. Subsequently, his dose was changed to $120 \mathrm{mg}$ per day for the first two weeks and $80 \mathrm{mg}$ per day for the third week. After 15 months of treatment, a flexible sigmoidoscopy was performed and showed an ulcerative non-obstructive mass at the site of the primary tumor which was biopsied and confirmed residual poorly differentiated adenocarcinoma. A repeat 200 gene NGS panel was performed on this biopsy and identified KRAS G12S, TP53 R273C, and $A P C I 742 f s^{*}$ which were previously reported at time of diagnosis. However, new gene alterations were identified in ataxia telangiectasia and $\operatorname{Rad} 3$ related $(A T R)$ gene at codon I774fs*; and gene amplifications in v-myc avian myelocytomatosis viral oncogene lung carcinoma derived homolog $(M Y C L)$, cyclin dependent kinase 4 (CDK4), and $K R A S$. Figure 1 showed the maximum response of the liver metastases after 17 months of regorafenib treatment.

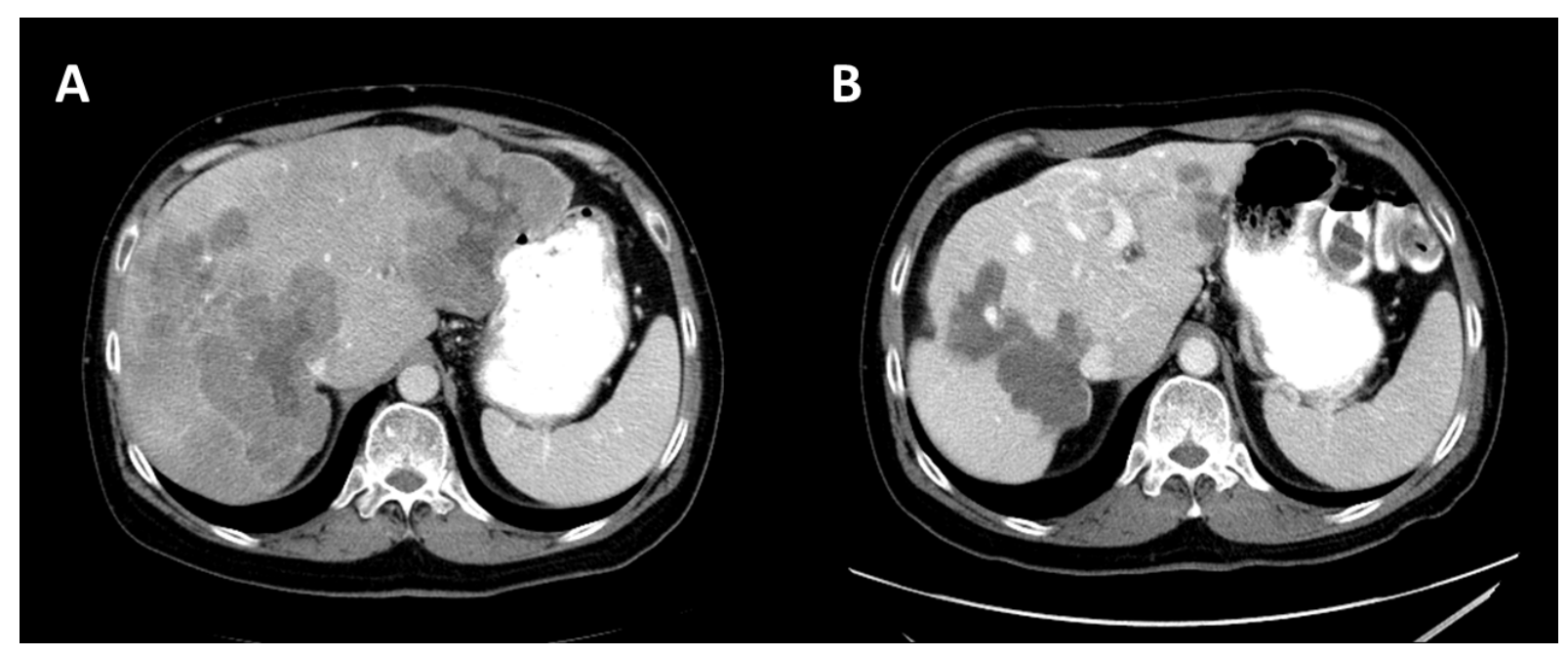

Figure 1: Abdominal CT with contrast (A) at baseline showed multiple liver masses, largest $9.8 \times 9.5 \mathrm{~cm}$. in the left lobe and $11.6 \times 9.8 \mathrm{~cm}$ in the right lobe (B) At best response, the liver masses were $5.4 \times 4 \mathrm{~cm}$ in the left lobe and $8.3 \times 9.5 \mathrm{~cm}$ in the right lobe. 
Table 1: NGS panel results as assessed longitudinally throughout the course of a patient with an exceptional response to regorafenib.

\begin{tabular}{|c|c|c|c|c|}
\hline Gene & $\begin{array}{l}\text { Diagnostic Biopsy } \\
\text { (Pre-treatment) }\end{array}$ & $\begin{array}{c}\text { Biopsy of Primary } \\
\text { Tumor after Partial } \\
\text { Response }\end{array}$ & $\begin{array}{c}\text { Biopsy of Primary } \\
\text { Tumor at Time of } \\
\text { Discordant Response }\end{array}$ & $\begin{array}{l}\text { ctDNA Sequencing } \\
\text { at Time of Systemic } \\
\text { Progression }\end{array}$ \\
\hline Platform used & $\mathrm{T} 200$ & T200.1 & T200.1 & Guardant 360 \\
\hline$K R A S \mathrm{G} 12 \mathrm{~S}$ & $\checkmark$ & $\checkmark$ & $\checkmark$ & $\checkmark$ \\
\hline TP53 R273C & $\checkmark$ & $\checkmark$ & $\checkmark$ & $\checkmark$ \\
\hline TP53 R175H & $\mathrm{x}$ & $\mathrm{x}$ & $\mathrm{x}$ & $\checkmark$ (minor alteration) \\
\hline$A P C \mathrm{R} 1450^{*}$ & $\checkmark$ & $\mathrm{x}$ & $\mathrm{x}$ & $\mathrm{x}$ \\
\hline$A P C$ I742fs* & $\checkmark$ & $\checkmark$ & $\checkmark$ & $\checkmark$ (minor alteration) \\
\hline FLT4 F131S & $\checkmark$ & $\mathrm{x}$ & $\mathrm{x}$ & $\mathrm{x}$ \\
\hline PPP1R3A E271D & $\checkmark$ & $\mathrm{x}$ & $\mathrm{x}$ & $\mathrm{x}$ \\
\hline ATR I774fs* & $\mathrm{x}$ & $\checkmark$ & $\mathrm{x}$ & $\mathrm{x}$ \\
\hline EP300 L1755V & $\mathrm{x}$ & $\mathrm{x}$ & $\checkmark$ & $\mathrm{x}$ \\
\hline WHSC1L1 E123Q & $\mathrm{x}$ & $\mathrm{x}$ & $\checkmark$ & $\mathrm{x}$ \\
\hline KIT G691S & $\mathrm{x}$ & $\mathrm{x}$ & $\mathrm{x}$ & $\checkmark$ \\
\hline$M Y C L$ amplification & $\mathrm{x}$ & $\checkmark(7.4)^{*}$ & $\checkmark(2.5)^{*}$ & $\mathrm{x}$ \\
\hline$C D K 4$ amplification & $\mathrm{x}$ & $\checkmark(3.1)^{*}$ & $\checkmark(2.7)^{*}$ & $\checkmark(2.4) *$ \\
\hline$K R A S$ amplification & $\mathrm{x}$ & $\checkmark(3.1)^{*}$ & $\mathrm{x}$ & $\checkmark(2.4)^{*}$ \\
\hline FGFR1 amplification & $\mathrm{x}$ & $\mathrm{x}$ & $\checkmark(2.5)^{*}$ & $\checkmark(2.46)^{*}$ \\
\hline$E G F R$ amplification & $\mathrm{x}$ & $\mathrm{x}$ & $\checkmark(2.7)^{*}$ & $\checkmark(2.5)^{*}$ \\
\hline MYC amplification & $\mathrm{x}$ & $\mathrm{x}$ & $\mathrm{x}$ & $\checkmark(2.49)^{*}$ \\
\hline PIK3CA amplification & $\mathrm{x}$ & $\mathrm{x}$ & $\mathrm{x}$ & $\checkmark(2.58)^{*}$ \\
\hline
\end{tabular}

$K R A S$; Kirsten rat sarcoma viral oncogene homolog, TP53; tumor protein p53, APC; adenomatous polyposis coli, FT4; FmsRelated Tyrosine Kinase, PPP1R3A; protein phosphatase 1 regulatory subunit 3A, ATR; ataxia telangiectasia and Rad3 related, EP300; E1A binding protein p300, WHSC1L1; Wolf-Hirschhorn Syndrome Candidate 1-Like 1, KIT; KIT proto-oncogene receptor tyrosine kinase, $M Y C L$; v-myc avian myelocytomatosis viral oncogene lung carcinoma derived homolog, $C D K 4$; cyclin dependent kinase 4,FGFR1; fibroblast growth factor receptor 1, EGFR; epidermal growth factor receptor, $P I K 3 C A$; phosphatidylinositol-4,5-bisphosphate 3-kinase catalytic subunit alpha, ctDNA; circulating tumor DNA, *copy number

Treatment with regorafenib was continued with good tolerance. After 20 months of regorafenib a CT scan of the abdomen showed stable liver metastases but increased size of the rectal mass. Re-biopsy of the rectal tumor was obtained to assess for mechanisms of resistance and sequencing identified FGFRI and EGFR gene amplifications; and an E1A binding protein p300 (EP300) mutation in codon L1755V, and a WolfHirschhorn Syndrome Candidate 1-Like 1 (WHSC1L1) mutation in codon E123Q. Concurrent chemo-radiation (CCRT) therapy with capecitabine $650 \mathrm{mg} / \mathrm{m} 2$ twice daily with a total of $50.4 \mathrm{~Gy}$ was initiated and regorafenib was placed on hold. Upon completion of CCRT, regorafenib was re-initiated with continued disease control in the liver. Unfortunately, after 27 months of regorafenib treatment, an abdominal CT revealed progression of the liver metastases. Re-biopsy of the liver was attempted but there were no viable cells to characterize. Therefore, circulating tumor DNA (ctDNA) sequencing was used to characterize alterations after regorafenib progression. Analysis revealed a mutation in KIT at codon G961S, PIK3CA and MYC gene amplifications that were not noted on prior testing and confirmed FGFRI and EGFR amplifications which were previously identified in the progressed rectal tumor tissue. The mutational profile is summarized in Table 1 and Supplementary Table 1.

As the patient had not received any other prior anti-VEGF therapy, he was started on irinotecan plus aflibercept. Restaging CT scans after 2 and 4 months showed stable disease, however the patient developed grade III diarrhea during therapy leading to the omission of subsequent irinotecan after 4 months. The patient continued aflibercept for a further 2 months at which point he was found to have hepatic progression. The patient was subsequently transitioned to best supportive care.

\section{DISCUSSION}

We report the case of an exceptional responder to regorafenib in $\mathrm{mCRC}$ and describe the alterations identified through molecular testing, anticipating to elucidate a potential mechanism of sensitivity in this patient.

Regorafenib, an oral mutikinase inhibitor, can inhibit activity of several protein kinases, including those involved in tumor proliferation (KIT, PDGFR and 
RET), tumor angiogenesis (VEGFR1-3, TIE2), and tumor microenvironment (PDGFR-B, FGFR) [5, 8, 9]. The Food and Drug Administration approved regorafenib in 2012 for the treatment of $\mathrm{mCRC}$ after failure of standard therapies, including fluoropyrimidine, oxaliplatin, and irinotecanbased chemotherapy, anti-VEGR therapy, and anti-EGFR therapy in $K R A S$ wild type tumors. Regorafenib showed benefit in both KRAS-wild-type and KRAS-mutant subgroups $[1,2]$.

Prior attempts to identify a useful biomarker to select patients who will benefit from regorafenib have assessed stereotypic mCRC aberrant genes including $K R A S, B R A F$, $P I K 3 C A$, and MMR status and failed to correlate mutations in any of these genes to treatment response [2, 3]. Teufel et al suggested a benefit of regorafenib therapy in patients with high-risk molecular characteristics defined by gene expression clusters $(\mathrm{HR}=0.10 ; 95 \% \mathrm{CI} 0.02-0.35)$ compared to a lower-risk subgroup ( $\mathrm{HR}=0.58 ; 95 \% \mathrm{CI}$ $0.44-0.77$ ) although this has not yet been validated [3] Moreover, markers of angiogenesis may have potential utility in identifying responders. Eisen et al reported higher baseline TIMP metallopeptidase inhibitor 2 (TIMP2) and soluble tyrosine kinase with immunoglobulin like and EGF like domains 1 (TIE1) which were correlated with regorafenib treatment response [10]. Data from CORRECT [3] also demonstrated that high levels of soluble protein TIE1 were associated with OS benefit in the regorafenib group. Additionally, Giampieri et al reported that patients who harbored VEGF-A rs2010963 germline polymorphism showed better PFS $(\mathrm{HR}=0.49$, 95\%CI 0.33-0.81) and OS (HR 0.52, 95\%CI 0.34-0.99) when treated with regorafenib compared to those without these polymorphisms [8]. While hypothesis generating, all of these angiogenic markers suffer from limited power due to multiple comparison and require further studies.

The patient reported here had an exceptional response to regorafenib of 27 months, which has never been reported previously. The most recent published data from Japan [11] reported 18 months of partial response in a patient with $\mathrm{mCRC}$ treated after progression on FOLFOX, FOLFIRI, and XELOX regimens. However, they did not report any molecular analysis. In this study, we utilized sequential molecular testing before, during, and upon progression of regorafenib treatment. We found several gene mutations, including KRAS codon G12S, TP53 codon $R 273 C$, and $A P C$ codon I742fs*which persisted from diagnosis through treatments. We also found several transient mutations that occurred during regorafenib treatment including $A P C$ codon R1450*, PPP1R3A codon E271D, ATR gene in codon I774fs*, EP300 codon L1755V, and WHSC1L1 codon E123Q. However, these genes do not have biologic rationale to support their use as a predictive biomarker, and instead likely reflect clonal diversity over time.

FLT4 mutations are rare in CRC and have been reported in only $2.4 \%(5 / 212)$ in sequenced CRC in the Cancer Genomic Atlas (TCGA) dataset [12, 13]. FLT4 F131S located within the extracellular region of FLT4 protein [14]. Previously FLT4 F131S has not been functionally characterized; therefore this mutation was functionally analyzed in the $\mathrm{Ba} / \mathrm{F} 3$ system which revealed that this mutation does not induce growth factor independent cell growth and thus is characterized as likely non-transforming/benign. Nevertheless, it cannot be ruled out that FLT4 mutations might sensitize cells/ tumors to regorafenib treatment. Further experiments that characterize this mutation with regards to its therapeutic effect might be needed.

The mechanisms of pre-existing and acquired resistance to regorafenib are unknown. Recent data from a pre-clinical study demonstrated Notch-I upregulation in regorafenib resistant tumor cells and inhibition of Notch-I in resistant cells partially restored sensitivity to the regorafenib treatment in vitro. These results suggest Notch as potential mechanism of acquired resistance [15]. Gene amplifications are a common mechanism of acquired resistance to targeted therapies in CRC. Examples include $B R A F$ gene amplification in MEK inhibitor treated tumor [16] , HER2 and MET amplification in anti-EGFRab treated tumor $[17,18]$. Many acquired gene amplifications were identified in the patient's tumor profile (Table $1)$; several of these amplifications were present in the responding tumor $(M L C L, C D K 4$, and $K R A S)$ and are less likely to be associated with resistance. Others such as $M Y C$ and $P I K 3 C A$ were only present in the cfDNA but not seen in the progressing rectal primary. In contrast $F G F R 1$ and $E G F R$ were present at the time of progression of the rectal primary and later upon progression of the liver metastases, and are therefore candidate resistance mechanism.

FGFR1 is a gene that encodes a member of FGFR family which includes four receptor tyrosine kinases, FGFR1-4 [19]. FGFR1 gene amplification has been reported in numerous malignancies including breast cancer and squamous cell carcinoma of lung cancer, head and neck cancer, and esophageal cancer [20-23]. FGFR1 amplifications have been reported in $2.8 \%$ (6 cases) of 212 sequenced CRC in the TCGA dataset $[12,13]$. Although FGFR1 has recently emerged as a promising target in non-small cell lung cancer, data from CRC are limited. EGFR belongs to a family of cell signaling receptors and is known to activate a cascade of multiple signaling pathways. The presence of an EGFR abnormality; including mutation, amplification, and overexpression, can result in over activity of EGFR protein and excessive proliferation [24]. EGFR amplifications have been reported in $0.5 \%$ ( 1 case) of 212 sequenced CRC in the TCGA dataset $[12,13]$. Although EGFR mutations have been reported to predict sensitivity to EGFR tyrosine kinase inhibitors in lung cancer [25], little is known about the impact of EGFR amplifications in either for selecting patient to anti-EGFR treatment or as a role in resistance. 
Each of the above amplifications were noted in pathways that are adjacent or in line with a pathway targeted by regorafenib and our molecular characterization shows multiple concurrent potential resistance mechanisms induced by regorafenib. However, to our knowledge, no gene amplification has previously been established as a potential resistance mechanism for regorafenib.

$K I T$ was the only mutation noted upon tumor progression during regorafenib. KIT encodes the human homolog of the proto-oncogene c-kit that belongs to the type III tyrosine kinase receptor family [26]. Binding of its endogenous ligand, stem cell factor (SCF) initiates multiple downstream signaling pathways [27-29]; including mitogen-activated protein kinase (MAPK) pathway, phosphatidylinositol 3-kinase (PI3K)/ AKT pathway, Janus kinase/signal transducers and activators of transcription (JAK/STAT) pathway, PLC- $\gamma$ signaling transduction pathway and Src kinase signaling transduction pathway, leading to cell proliferation, survival and migration. KIT mutations have been reported in $2.8 \%(6 / 212)$ of sequenced CRC in the TCGA dataset $[12,13]$. KIT G961S alteration has not been functionally characterized. It is located at the $\mathrm{C}$-terminal end of the protein, outside of any known function domain [14]. Although, KIT G916S has not been reported with any clinical significance, the acquisition of any mutation in a kinase targeted by regorafenib suggests that KIT G961S might play a role in acquired resistance.

\section{CONCLUSION}

We report a case with an unusually prolonged response to regorafenib in $\mathrm{mCRC}$ and we highlight the development of FGFR1/EGFR amplifications and a KIT G961S mutation as potential mechanisms of acquired resistance in this patient. The molecular features of this exceptional responder may provide insight into genomic alterations that develop during regorafenib treatment which may lead to acquired resistance.

\section{APPENDICES}

\section{Methods}

\section{T200 gene panel}

The T200 is a next generation sequencing panel that provides sequencing coverage of all exons for 201 cancer related genes. The panel consists of 4874 exons encoding 938607 bases and was designed with a higher read depth in order to provide the ability to call mutations at lower allele frequencies (down to 1\%). Detailed methods associated with this assay have been previously published [30].

\section{Guardant 360TM assays}

The Guardant 360TM is a commercially available next generation sequencing panel developed for use with circulating tumor DNA (ctDNA). The panel consists of 68 cancer related genes and is able to identify mutations and copy number alterations. Cell free DNA is extracted from plasma and genomic alterations are analyzed by massively parallel sequencing of amplified target genes. The minimum detectable mutant allele is dependent on the concentration of ctDNA in a patient's serum at the time of blood draw [31].

\section{CIMP methylation}

Assay is performed using either formalin-fixed, paraffin-embedded tissue blocks or frozen tissue samples. DNA extracted from formalin-fixed, paraffinembedded tissue or frozen tissue samples is treated with bisulfite to convert unmethylated cytosine to uracil. PCR amplification of both unmethylated and methylated MINT1, MINT2 and MINT31 loci, and promoter sequences of p14, p16 and hMLH1 genes is performed and methylation status is assessed by pyrosequencing. The tumor is considered CIMP High, if at least $40 \%$ of markers tested show methylation, and CIMP Low if $<40 \%$ markers show methylation.

\section{IL3 dependency Ba/F3 assay}

An IL-3 dependent murine $\mathrm{Ba} / \mathrm{F} 3$ cell reporter model was used to evaluate the functional impact of a FLT4 F131S mutation. The procedure was same as described previously [32] with few modifications. Briefly, this pro-B cell line is dependent on IL-3 for proliferation. Oncogenic transformation with a mutation results in IL-3 independent growth, thus highlighting a functionally significant mutation. $\mathrm{Ba} / \mathrm{F} 3$ cells were introduced with FLT4 F131S mutant using lentivirus approach and incubated in medium with $0.5 \mathrm{pg} / \mathrm{ml} \mathrm{IL-3} \mathrm{which} \mathrm{is}$ $0.01 \%$ of regular IL-3 concentration used in cell line maintenance. Trace amount of IL-3 in medium delays IL-3 depletion-mediated cell death and gives time to the cells to adapt oncogenic mutant. Cell viability was measured after $1,1.5$, and 2 weeks.

\section{ACKNOWLEDGMENTS}

The authors are grateful to Dr.Kwok shing $\mathrm{Ng}, \mathrm{PhD}$ for helping with the completeness of functional genomic data

\section{FUNDING}

This study was funded by ROI CA 172670 (SK).

\section{CONFLICTS OF INTEREST}

All authors have no conflict of interest to declare. 
Data Deposition and Access: Genetic variant data was submitted to ClinVar (https://www.ncbi.nlm.nih.gov/ clinvar) under submission ID: SUB2525808.

Ethic Statement: Written informed consent for publication of this case report was obtained from the patient under protocol number 2009-0091 (The Assessment of Targeted Therapies Against Colorectal Cancer-ATTACC program).

\section{REFERENCES}

1. Grothey A, Van Cutsem E, Sobrero A, Siena S, Falcone A, Ychou M, Humblet Y, Bouché O, Mineur L, Barone C, Adenis A, Tabernero J, Yoshino T, et al. Regorafenib monotherapy for previously treated metastatic colorectal cancer (CORRECT): an international, multicentre, randomised, placebo-controlled, phase 3 trial. Lancet. 2013; 381:303-312.

2. Li J, Qin S, Xu R, Yau TC, Ma B, Pan H, Xu J, Bai Y, Chi Y, Wang L, Yeh KH, Bi F, Cheng Y, et al. Regorafenib plus best supportive care versus placebo plus best supportive care in Asian patients with previously treated metastatic colorectal cancer (CONCUR): a randomised, double-blind, placebo-controlled, phase 3 trial. Lancet Oncol. 2015; 16:619-629.

3. Tabernero J, Lenz HJ, Siena S, Sobrero A, Falcone A, Ychou M, Humblet Y, Bouché O, Mineur L, Barone C, Adenis A, Yoshino T, Goldberg RM, et al. Analysis of circulating DNA and protein biomarkers to predict the clinical activity of regorafenib and assess prognosis in patients with metastatic colorectal cancer: a retrospective, exploratory analysis of the CORRECT trial. Lancet Oncol. 2015; 16:937-948.

4. Galland F, Karamysheva A, Pebusque MJ, Borg JP, Rottapel R, Dubreuil P, Rosnet O, Birnbaum D. The FLT4 gene encodes a transmembrane tyrosine kinase related to the vascular endothelial growth factor receptor. Oncogene. 1993; 8:1233-1240.

5. Wilhelm SM, Dumas J, Adnane L, Lynch M, Carter CA, Schütz G, Thierauch KH, Zopf D. Regorafenib (BAY 73-4506): a new oral multikinase inhibitor of angiogenic, stromal and oncogenic receptor tyrosine kinases with potent preclinical antitumor activity. Int J Cancer. 2011; 129:245255.

6. Abajo A, Bitarte N, Zarate R, Boni V, Lopez I, GonzalezHuarriz M, Rodriguez J, Bandres E, Garcia-Foncillas J. Identification of colorectal cancer metastasis markers by an angiogenesis-related cytokine-antibody array. World J Gastroenterol. 2012; 18:637-645.

7. Eisenhauer EA, Therasse P, Bogaerts J, Schwartz LH, Sargent D, Ford R, Dancey J, Arbuck S, Gwyther S, Mooney M, Rubinstein L, Shankar L, Dodd L, et al. New response evaluation criteria in solid tumours: revised RECIST guideline (version 1.1). Eur J Cancer. 2009; 45:228-247.
8. Mross K, Frost A, Steinbild S, Hedbom S, Büchert M, Fasol U, Unger C, Krätzschmar J, Heinig R, Boix O, Christensen O. A phase I dose-escalation study of regorafenib (BAY 734506), an inhibitor of oncogenic, angiogenic, and stromal kinases, in patients with advanced solid tumors. Clin Cancer Res. 2012; 18:2658-2667.

9. Strumberg D, Schultheis B. Regorafenib for cancer. Expert Opin Investig Drugs. 2012; 21:879-889.

10. Eisen T, Joensuu H, Nathan PD, Harper PG, Wojtukiewicz MZ, Nicholson S, Bahl A, Tomczak P, Pyrhonen S, Fife K, Bono P, Boxall J, Wagner A, et al. Regorafenib for patients with previously untreated metastatic or unresectable renalcell carcinoma: a single-group phase 2 trial. Lancet Oncol. 2012; 13:1055-1062.

11. Iseki Y, Yashiro M, Shibutani M, Nagahara H, Maeda K, Matsutani S, Tamura T, Ohira G, Yamazoe S, Kimura K, Toyokawa T, Amano R, Tanaka H, et al. [A Case of Metastatic Lung Cancer from Colon Cancer with a Long Partial Response with Regorafenib Treatment]. [Article in Japanese]. Gan To Kagaku Ryoho. 2016; 43:2338-2340.

12. Cerami E, Gao J, Dogrusoz U, Gross BE, Sumer SO, Aksoy BA, Jacobsen A, Byrne CJ, Heuer ML, Larsson E, Antipin Y, Reva B, Goldberg AP, et al. The cBio cancer genomics portal: an open platform for exploring multidimensional cancer genomics data. Cancer Discov. 2012; 2:401-404.

13. Gao J, Aksoy BA, Dogrusoz U, Dresdner G, Gross B, Sumer SO, Sun Y, Jacobsen A, Sinha R, Larsson E, Cerami E, Sander C, Schultz N. Integrative analysis of complex cancer genomics and clinical profiles using the cBioPortal. Sci Signal. 2013; 6:pl1.

14. Consortium U. UniProt: a hub for protein information. Nucleic Acids Res. 2015; 43:D204-212.

15. Mirone G, Perna S, Shukla A, Marfe G. Involvement of Notch-1 in Resistance to Regorafenib in Colon Cancer Cells. J Cell Physiol. 2016; 231:1097-1105.

16. Corcoran RB, Dias-Santagata D, Bergethon K, Iafrate AJ, Settleman J, Engelman JA. BRAF gene amplification can promote acquired resistance to MEK inhibitors in cancer cells harboring the BRAF V600E mutation. Sci Signal. 2010; 3:ra84.

17. Yonesaka K, Zejnullahu K, Okamoto I, Satoh T, Cappuzzo F, Souglakos J, Ercan D, Rogers A, Roncalli M, Takeda M, Fujisaka Y, Philips J, Shimizu T, et al. Activation of ERBB2 signaling causes resistance to the EGFR-directed therapeutic antibody cetuximab. Sci Transl Med. 2011; 3:99ra86.

18. Leto SM, Trusolino L. Primary and acquired resistance to EGFR-targeted therapies in colorectal cancer: impact on future treatment strategies. J Mol Med (Berl). 2014; 92:709722.

19. Dienstmann R, Rodon J, Prat A, Perez-Garcia J, Adamo B, Felip E, Cortes J, Iafrate AJ, Nuciforo P, Tabernero J. Genomic aberrations in the FGFR pathway: opportunities for targeted therapies in solid tumors. Ann Oncol. 2014; 
25:552-563

20. André F, Bachelot T, Commo F, Campone M, Arnedos M, Dieras V, Lacroix-Triki M, Lacroix L, Cohen P, Gentien D, Adélaide J, Dalenc F, Goncalves A, et al. Comparative genomic hybridisation array and DNA sequencing to direct treatment of metastatic breast cancer: a multicentre, prospective trial (SAFIR01/UNICANCER). Lancet Oncol. 2014; 15:267-274.

21. Freier K, Schwaenen C, Sticht C, Flechtenmacher C, Mühling J, Hofele C, Radlwimmer B, Lichter P, Joos S. Recurrent FGFR1 amplification and high FGFR1 protein expression in oral squamous cell carcinoma (OSCC). Oral Oncol. 2007; 43:60-66.

22. Bandla S, Pennathur A, Luketich JD, Beer DG, Lin L, Bass AJ, Godfrey TE, Litle VR. Comparative genomics of esophageal adenocarcinoma and squamous cell carcinoma. Ann Thorac Surg. 2012; 93:1101-1106.

23. Jiang T, Gao G, Fan G, Li M, Zhou C. FGFR1 amplification in lung squamous cell carcinoma: a systematic review with meta-analysis. Lung Cancer. 2015; 87:1-7.

24. Ciardiello F, Tortora G. EGFR antagonists in cancer treatment. N Engl J Med. 2008; 358:1160-1174.

25. Mok TS, Wu YL, Thongprasert S, Yang CH, Chu DT, Saijo N, Sunpaweravong P, Han B, Margono B, Ichinose Y, Nishiwaki Y, Ohe Y, Yang JJ, et al. Gefitinib or carboplatin-paclitaxel in pulmonary adenocarcinoma. N Engl J Med. 2009; 361:947-957.
26. Pawson T. Regulation and targets of receptor tyrosine kinases. Eur J Cancer. 2002; 38:S3-10.

27. Fletcher JA. Role of KIT and platelet-derived growth factor receptors as oncoproteins. Semin Oncol. 2004; 31:4-11.

28. Hendriks RW. Drug discovery: New Btk inhibitor holds promise. Nat Chem Biol. 2011; 7:4-5.

29. Summy JM, Gallick GE. Treatment for advanced tumors: SRC reclaims center stage. Clin Cancer Res. 2006; 12:13981401.

30. Chen K, Meric-Bernstam F, Zhao H, Zhang Q, Ezzeddine N, Tang LY, Qi Y, Mao Y, Chen T, Chong Z, Zhou W, Zheng X, Johnson A, et al. Clinical actionability enhanced through deep targeted sequencing of solid tumors. Clin Chem. 2015; 61:544-553.

31. Lanman RB, Mortimer SA, Zill OA, Sebisanovic D, Lopez R, Blau S, Collisson EA, Divers SG, Hoon DS, Kopetz ES, Lee J, Nikolinakos PG, Baca AM, et al. Analytical and Clinical Validation of a Digital Sequencing Panel for Quantitative, Highly Accurate Evaluation of Cell-Free Circulating Tumor DNA. PLoS One. 2015; 10:e0140712.

32. Dogruluk T, Tsang YH, Espitia M, Chen F, Chen T, Chong Z, Appadurai V, Dogruluk A, Eterovic AK, Bonnen PE, Creighton CJ, Chen K, Mills GB, et al. Identification of Variant-Specific Functions of PIK3CA by Rapid Phenotyping of Rare Mutations. Cancer Res. 2015; 75:5341-5354. 